\title{
Endothelial dysfunction is associated with a greater depressive symptom score in a general elderly population: the Hoorn Study
}

Citation for published version (APA):

van Sloten, T. T., Schram, M. T., Adriaanse, M. C., Dekker, J. M., Nijpels, G., Teerlink, T., Scheffer, P. G., Pouwer, F., Schalkwijk, C. G., Stehouwer, C. D. A., \& Henry, R. M. A. (2014). Endothelial dysfunction is associated with a greater depressive symptom score in a general elderly population: the Hoorn Study. Psychological Medicine, 44(7), 1403-1416. https://doi.org/10.1017/S0033291713002043

Document status and date:

Published: 01/05/2014

DOI:

10.1017/S0033291713002043

Document Version:

Publisher's PDF, also known as Version of record

\section{Document license:}

Taverne

Please check the document version of this publication:

- A submitted manuscript is the version of the article upon submission and before peer-review. There can be important differences between the submitted version and the official published version of record.

People interested in the research are advised to contact the author for the final version of the publication, or visit the DOI to the publisher's website.

- The final author version and the galley proof are versions of the publication after peer review.

- The final published version features the final layout of the paper including the volume, issue and page numbers.

Link to publication

\footnotetext{
General rights rights.

- You may freely distribute the URL identifying the publication in the public portal. please follow below link for the End User Agreement:

www.umlib.nl/taverne-license

Take down policy

If you believe that this document breaches copyright please contact us at:

repository@maastrichtuniversity.nl

providing details and we will investigate your claim.
}

Copyright and moral rights for the publications made accessible in the public portal are retained by the authors and/or other copyright owners and it is a condition of accessing publications that users recognise and abide by the legal requirements associated with these

- Users may download and print one copy of any publication from the public portal for the purpose of private study or research.

- You may not further distribute the material or use it for any profit-making activity or commercial gain

If the publication is distributed under the terms of Article 25fa of the Dutch Copyright Act, indicated by the "Taverne" license above, 


\title{
Endothelial dysfunction is associated with a greater depressive symptom score in a general elderly population: the Hoorn Study
}

\author{
T. T. van Sloten ${ }^{1,2,3}$ t, M. T. Schram ${ }^{1,2}$ t, M. C. Adriaanse ${ }^{4}$, J. M. Dekker ${ }^{4,5}$, G. Nijpels ${ }^{4}$, T. Teerlink $^{6}$, \\ P. G. Scheffer ${ }^{6}$, F. Pouwer ${ }^{7}$, C. G. Schalkwijk ${ }^{1,2}$, C. D. A. Stehouwer ${ }^{1,2,3}$ and R. M. A. Henry ${ }^{1,2 *}$ \\ ${ }^{1}$ Department of Medicine, Maastricht University Medical Centre, The Netherlands \\ ${ }^{2}$ Cardiovascular Research Institute Maastricht, Maastricht University Medical Centre, The Netherlands \\ ${ }^{3}$ School for Nutrition, Toxicology and Metabolism, Maastricht University Medical Centre, The Netherlands \\ ${ }^{4}$ EMGO Institute for Health and Care Research, VU University Medical Centre, Amsterdam, The Netherlands \\ ${ }^{5}$ Department of Epidemiology and Biostatistics, VU University Medical Centre, Amsterdam, The Netherlands \\ ${ }^{6}$ Metabolic Laboratory, Department of Clinical Chemistry, VU University Medical Centre, Amsterdam, The Netherlands \\ ${ }^{7}$ Centre of Research on Psychology in Somatic Diseases, Department of Medical Psychology and Neuropsychology, Tilburg University, \\ The Netherlands
}

Background. Endothelial dysfunction (ED), low-grade inflammation (LGI) and oxidative stress (OxS) may be involved in the pathobiology of depression. Previous studies on the association of these processes in depression have yielded contradictory results. We therefore investigated comprehensively, in a population-based cohort study, the association between ED, LGI and OxS on the one hand and depressive symptoms on the other.

\begin{abstract}
Method. We used data from the Hoorn Study and determined biomarkers of ED [flow-mediated dilatation (FMD), von Willebrand factor, soluble intercellular adhesion molecule 1 (sICAM-1), soluble vascular cell adhesion molecule 1, soluble thrombomodulin and soluble endothelial selectin], LGI [C-reactive protein, tumour necrosis factor- $\alpha$, interleukin 6 , interleukin 8, serum amyloid A, myeloperoxidase (MPO) and sICAM-1] and OxS (oxidized low density lipoprotein and MPO). Depressive symptoms were quantified by the Center for Epidemiologic Studies Depression Scale (CES-D) questionnaire ( $n=493$; age 68 years; $49.9 \%$ female). Regression analyses were performed with the use of biomarker $\mathrm{Z}$ scores. Adjustments were made for age, sex and glucose metabolism status (cohort stratification variables) and prior cardiovascular disease, hypertension, waist-to-hip ratio, cholesterol levels, education level, physical activity, dietary habits, and the use of antihypertensive and/or lipid-lowering medication and/or metformin (potential confounders).
\end{abstract}

Results. After adjustment for age, sex and glucose metabolism status, one standard deviation increase in the ED Z score was associated with a 1.9 [95\% confidence interval (CI) 0.7-3.1] higher CES-D score. Additional adjustments did not materially change this result. LGI and OxS were not associated with the CES-D score.

Conclusions. ED, as quantified by an array of circulating biomarkers and FMD, was independently associated with depressive symptoms. This study supports the hypothesis that ED plays an important role in the pathobiology of depression.

Received 23 August 2012; Revised 11 July 2013; Accepted 21 July 2013; First published online 13 August 2013

Key words: Depression, endothelial dysfunction, low-grade inflammation, oxidative stress.

\section{Introduction}

The pathobiology of depression is complex. It has been suggested that endothelial dysfunction (ED), lowgrade inflammation (LGI) and oxidative stress (OxS)

* Address for correspondence: R. M. A. Henry, Ph.D., M.D., Department of Medicine, Maastricht University Medical Centre, Prof. Debyelaan 25, 6229 HX Maastricht, The Netherlands.

(Email: rma.henry@mumc.nl)

+ These authors contributed equally to this work. are involved, as these phenomena may interfere with neurotransmitter metabolism, the hypothalamicpituitary-adrenal (HPA) axis and the homeostatic process of neurogenesis in the brain (Belmaker \& Agam, 2008; Dantzer et al. 2008; Miller et al. 2009; Krishnan $\&$ Nestler, 2010). However, these observations derive primarily from studies in animals. In humans, the study of these phenomena in the pathobiology of depression is more complicated. One approach is to study ED, LGI and OxS through the determination of biomarkers in peripheral blood, which assumes that 
ED, LGI and OxS are generalized phenomena and that each of these phenomena represents ED, LGI or OxS either directly or indirectly in the brain.

The concepts of ED (Aird, 2007a,b), LGI (Miller et al. 2009) and OxS (Maes et al. 2011) are heterogeneous in nature. These concepts can be defined individually in many different ways without it being clear that one definition necessarily favours the other in relation to depression. For example, ED has been defined as brachial artery impaired flow-mediation (Sherwood et al. 2005), but also by an increased level of circulating biomarkers [e.g. soluble vascular cell adhesion molecule 1 (sVCAM-1), soluble endothelial selectin (sE-selectin), soluble thrombomodulin (sTM)] (Do et al. 2010; Thomas et al. 2007). In addition, many different circulating biomarkers have been used to assess LGI [e.g. C-reactive protein (CRP), interleukin 6 (IL-6) and IL-1, and tumour necrosis factor- $\alpha$ (TNF- $\alpha$ )] (Tiemeier et al. 2003; Howren et al. 2009) and OxS [e.g. myeloperoxidase (MPO) and oxidized low density lipoprotein (oxLDL)] (Kupper et al. 2009; Maes et al. 2010). Furthermore, some studies have used a single biomarker to define the concepts of ED/LGI/OxS (Lesperance et al. 2004; Sherwood et al. 2005) whereas others have used multiple markers (Tiemeier et al. 2003; Do et al. 2010). The different definitions of the concepts of ED/LGI/OxS are exemplified by the fact that studies on the association between biomarkers of ED (Thomas et al. 2007; Pizzi et al. 2008), LGI (Tiemeier et al. 2003; Lesperance et al. 2004) and/or OxS (Forlenza \& Miller, 2006; Kupper et al. 2009) and depression have yielded inconsistent results (Ford \& Erlinger, 2004; Panagiotakos et al. 2004; Empana et al. 2005; Sherwood et al. 2005; Rybakowski et al. 2006; Narita et al. 2007; Elovainio et al. 2009; Schott et al. 2009; Cooper et al. 2010; Do et al. 2010; Maes et al. 2010; Paranthaman et al. 2010). In addition, these inconsistent results may be explained by the manner in which biomarkers of ED, LGI and/or OxS were determined (e.g. different laboratory techniques), the manner in which depression was assessed (e.g. interview versus questionnaire) and the populations investigated (e.g. clinical- versus population-based studies).

Nevertheless, and taken together, many studies (Tiemeier et al. 2003; Ford \& Erlinger, 2004; Lesperance et al. 2004; Panagiotakos et al. 2004; Elovainio et al. 2009; Howren et al. 2009) have found a positive association between LGI and depression, particularly for the LGI biomarkers CRP and the interleukins IL-6 and IL-1, most notably in clinical-based sampled studies and in studies in which depression was assessed by interview (Howren et al. 2009). For ED the evidence is less clear. In relatively small and/or selected populations (Sherwood et al. 2005; Rybakowski et al. 2006; Narita et al. 2007; Pizzi et al.
2008; Cooper et al. 2010) in particular, flow-mediated dilatation (FMD) was associated with depression to such an extent that a smaller FMD response was associated with more severe depressive symptoms. With regard to OxS, no clear picture emerges. Previous studies (Forlenza \& Miller, 2006; Kupper et al. 2009; Maes et al. 2011) have defined OxS in many different ways and have yielded contradictory results. Importantly, most of these studies examined ED, LGI and OxS in isolation whereas these processes are biologically inter-related and may therefore be interdependent (Stehouwer et al. 2002).

In view of these considerations, we investigated comprehensively, in a population-based study, the relationship between ED, LGI and OxS on the one hand and depressive symptoms on the other. In addition, we investigated whether any such associations were independent of diabetes, prior cardiovascular disease (CVD), physical activity, dietary habits and socioeconomic status. Finally, we investigated whether ED, LGI and OxS were associated with depressive symptoms independently of each other.

\section{Method \\ Study design}

For the current study, we used cross-sectional data from the 2000 Hoorn Study. The Hoorn Study, which started in 1989, is a population-based cohort study of glucose metabolism in relation to CVD risk factors (Mooy et al. 1995; Spijkerman et al. 2002; Henry et al. 2003). In brief, 2484 men and women, aged 50-75 years, from the population register of the medium-sized Dutch town of Hoorn participated in the baseline examination. In 1996-1998 (visit 2), 1513 (73\%) of all surviving participants agreed to participate in the first follow-up. In 2000 (visit 3), all of those who were diagnosed as having diabetes during the previous examinations $(n=176)$ and random samples of individuals with normal glucose metabolism $(n=705)$ and impaired glucose metabolism $(n=193)$ were invited, of whom 648 (60\%) participated. The local ethics committee approved the study and all participants gave their written informed consent.

\section{Depressive symptoms}

Depressive symptoms were assessed by a validated Dutch version of the 20-item Center for Epidemiologic Studies Depression Scale (CES-D; Beekman et al. 1997). Scores on the CES-D range from 0 to 60 . Higher scores on this scale indicate the presence of more (severe) depressive symptoms. In the present study, the CES-D was used both as a continuous and as a dichotomous variable with a predefined cut-off level of 16 
(Beekman et al. 1997). The latter represents the presence of clinically relevant depressive symptoms.

\section{ED, LGI and OxS}

ED was assessed by FMD of the brachial artery according to the guidelines of the International Brachial Artery Reactivity Task Force (Corretti et al. 2002), as described previously (Henry et al. 2004). In addition, ED was assessed by the quantification of the following circulating biomarkers: sVCAM-1, sE-selectin, sTM, soluble intercellular adhesion molecule 1 (sICAM-1) and von Willebrand factor (vWF). LGI was assessed by the quantification of high-sensitivity CRP, serum amyloid A (SAA), IL-6, IL-8, TNF- $\alpha$, MPO and sICAM-1. OxS was determined by the quantification of oxLDL and MPO.

In brief, serum biomarkers of ED (sVCAM-1, sE-selectin, sTM, sICAM-1) and LGI (CRP, SAA, IL-6, IL-8, TNF- $\alpha$ ) were assessed by a multi-array detection system based on electrochemiluminescence technology (SECTOR Imager 2400, Meso Scale Discovery, USA); details have been described elsewhere (van Bussel et al. 2011a). In addition, vWF was determined in citrated plasma by means of an enzyme-linked immunosorbent assay (ELISA) (van Bussel et al. 2011a), plasma oxLDL by competitive ELISA (Mercodia, Sweden) (van der Zwan et al. 2009) and MPO in ethylenediaminetetraacetic acid (EDTA) plasma by a sandwich ELISA (Mercodia) (Van der Zwan et al. 2010a).

In our laboratory, intra- and inter-assay coefficients of variation $(\mathrm{CVs})$ were respectively: $2.8 \%$ and $5.6 \%$ for sVCAM-1, 2.6\% and $6.7 \%$ for sE-selectin, $2.1 \%$ and $6.9 \%$ for sTM, $2.4 \%$ and $4.9 \%$ for sICAM-1, $2.8 \%$ and $4.0 \%$ for CRP, $2.7 \%$ and $11.6 \%$ for SAA, $5.6 \%$ and $13.0 \%$ for IL- $6,5.6 \%$ and $12.2 \%$ for IL- 8 , and $3.9 \%$ and $8.8 \%$ for TNF- $\alpha$. In addition, the intra- and inter-assay CVs were respectively $3.4 \%$ and $7.9 \%$ for vWF (van Bussel et al. 2011a), 6.7\% and 7.0\% for oxLDL (van der Zwan et al. 2009) and 3.9\% and 5.0\% for MPO (Van der Zwan et al. 2010a).

\section{Other measurements}

We determined medical history, education level, current medication use, anthropometrical (body height, weight, waist and hip circumference) and biological [blood pressure, total, high density lipoprotein (HDL) and LDL cholesterol, triglyceride and glucose levels, creatinine, albuminuria] variables as described elsewhere (Spijkerman et al. 2002; Henry et al. 2003). For assessment of glucose status, all participants, except those with previously diagnosed diabetes, underwent a standard 75-g oral glucose tolerance test and were classified as having normal glucose metabolism (NGM), impaired glucose metabolism (IGM; impaired fasting glucose and/or impaired glucose tolerance) or type 2 diabetes according to the 1999 World Health Organization criteria (Unwin et al. 2002). Smoking habits were categorized as current, former and nonsmokers. Hypertension was defined as a systolic blood pressure $(\mathrm{BP}) \geqslant 140 \mathrm{mmHg}$ and/or diastolic BP $\geqslant 90 \mathrm{mmHg}$ and/or the current use of antihypertensive medication. Estimated glomerular filtration rate (eGFR in $\mathrm{ml} / \mathrm{min} / 1.73 \mathrm{~m}^{2}$ ) was calculated according to the Modification of Diet in Renal Disease (MDRD) short formula (without assay calibration): $186 \times($ serum creatinine $)^{-1.154} \times(\text { age })^{-0.203} \times 1.212$ (if black) $\times 0.742$ (if female) (Levey et al. 2007). Education level was dichotomized as low (secondary school or less) versus higher education. Physical activity, expressed as metabolic equivalent of task (MET) h/week, was assessed by the Short Questionnaire to Assess Health-Enhancing Physical Activity (SQUASH; Wendel-Vos et al. 2003). Diet was assessed by a validated self-administered Food Frequency Questionnaire (FFQ; Ocke et al. 1997a,b; Du et al. 2008). In the FFQ, participants were asked to report habitual diet over the previous year (Ocke et al. 1997a,b). Based on the FFQ, we calculated the alternative Mediterranean diet (aMED) score as described by Fung et al. (2005). The aMED score quantifies 'diet quality' and is based on the dietary intake of vegetables, legumes, fruit, nuts, whole grains, meat, fish, unsaturated and saturated fat and ethanol.

\section{Statistical analysis}

All analyses were performed with PASW Statistics 18 (IBM, USA).

FMD was analysed as a functional marker of ED. For descriptive purposes, FMD values were reversed, that is multiplied by -1 (higher values indicating worse endothelial function), and an FMD $Z$ score was calculated according to the formula: (individual valuepopulation mean)/[population standard deviation (S.D.)]. In all statistical analyses, the FMD Z score was adjusted for baseline diameter, flow increase after cuff release and nitroglycerin-mediated dilatation (NMD).

For reasons of statistical efficiency and to reduce the influence of the biological variability of each measure, a circulating biomarker $Z$ score was determined for the individual circulating biomarkers of ED, LGI and OxS according to predefined clusters of conceptually related biomarkers (Jager et al. 1999; Yudkin et al. 1999; van Bussel et al. 2011b). The circulating biomarker $Z$ scores were calculated as follows: for each individual circulating biomarker, a $Z$ score was calculated. The resulting $Z$ scores were then averaged into the circulating biomarker $Z$ score for ED, LGI and OxS. The ED 
circulating biomarker $Z$ score consisted of scores for sVCAM-1, sE-selectin, sTM, sICAM-1 and vWF. In addition, we combined the FMD $Z$ score and the ED circulating biomarker $Z$ score into a 'total ED' score. The LGI circulating biomarker $Z$ score consisted of scores for CRP, SAA, IL-6, IL-8, TNF- $\alpha$, MPO and sICAM-1. As both monocytes and the endothelium express sICAM-1 (Schram \& Stehouwer, 2005), sICAM-1 was included in the $Z$ score of both LGI and ED. The OxS circulating biomarker $Z$ score consisted of oxLDL and MPO. As MPO is a measure of both oxidative stress and inflammation (Schindhelm et al. 2009), it was included in the $Z$ score of OxS and LGI. Linear and logistic regression analyses were used to evaluate the associations between, on the one hand, the total ED score, the FMD $Z$ score and the circulating biomarker $Z$ scores of ED, LGI and OxS and, on the other, depressive symptoms (CES-D score; the analyses were performed for both the continuous and the dichotomous CES-D score). We first adjusted, in all models, for the stratification variables of the Hoorn Study cohort: age, sex and glucose metabolism status (model 1). These associations were then additionally adjusted for the following sets of potential confounders (Panagiotakos et al. 2004; Empana et al. 2005; Pizzi et al. 2008): conventional CVD risk factors [prior CVD, hypertension, waist-to-hip ratio (WHR), triglycerides and total/HDL cholesterol (model 2)], lifestyle factors [education level, physical activity, smoking status and aMED score (model 3)] and the use of antihypertensive and/or lipid-lowering medication and/or metformin (model 4). In models 5-7, mutual adjustments were made for each of the individual $Z$ scores.

The association between ED, LGI or OxS and depression might be different according to sex (Ford \& Erlinger, 2004; Krishnan \& Nestler, 2010) or glucose metabolism status (Musselman et al. 2003). For instance, the hyperglycaemic state may amplify the effect of ED, LGI and/or OxS on depressive symptoms/ depression, even though the hyperglycaemic state itself enhances these processes. In addition, some studies have shown an association between LGI in men but not in women (Penninx et al. 2003; Ford \& Erlinger, 2004); this may be due to the effect of gonadal hormones on the level of plasma biomarkers (Ford \& Erlinger, 2004). To investigate these possible interactions, we added to our models interaction terms between sex and ED/LGI/OxS and between glucose metabolism status and ED/LGI/OxS.

A $p$ value $<0.05$ was considered statistically significant, except for the interaction analyses, where $p$ values $<0.10$ were used. Interaction analyses are handicapped in that they compare smaller subsets of study subjects and therefore have less power than the primary study analysis (Rothman et al. 2008). The use of a higher $p$ value is recommended (Selvin, 1996) to enable the detection of any potentially important interaction, even though such a greater $p$ value enhances the possibility of a type 1 error.

\section{Results}

\section{Participants}

Of the 648 participants, 84 had missing CES-D data and 14 had incomplete glucose data. In the remaining 550 participants, full data on circulating biomarkers of ED, LGI and OxS were available in 493 participants (study population), of whom 357 had FMD measurements of sufficient quality (i.e. clear visual definition of the arterial wall throughout the entire measurement; Henry et al. 2004). Participants with missing biomarker data were older (72 v. 69 years) and more often had type 2 diabetes $(40 \%$ v. $20 \%$; $p$ for all <0.05). Participants with missing FMD data were older (72 $v$. 68 years), more often had type 2 diabetes (35\% $v$. $17 \%$ ) and had a higher CES-D score (9 v. 6; $p$ for all $<0.05$ ). In addition, these participants had a worse CVD risk factor pattern (data not shown).

\section{Clinical characteristics}

Tables 1 and 2 show the characteristics of the study population according to the presence of clinically relevant depressive symptoms (i.e. CES-D score $\geqslant 16$ ). According to the CES-D cut-off level, 63 participants $(12.8 \%)$ had clinically relevant depressive symptoms. In persons with clinically relevant depressive symptoms compared to those without, the total ED score, the FMD $Z$ score and the circulating biomarker $Z$ scores of ED, LGI and OxS were higher.

\section{Association between ED, LGI and OxS and depressive symptoms}

The results of the linear regression analyses (CES-D expressed on a continuous scale) show that, after adjustment for age, sex and glucose metabolism status, 1 s.D. increase in the total ED score was associated with a higher CES-D score with a regression coefficient of 1.9 [95\% confidence interval (CI) 0.7-3.1] (Table 3, model 1; also illustrated in Fig. 1a). The LGI and OxS circulating biomarker $Z$ scores were not significantly associated with a higher CES-D score [regression coefficients 0.4 (95\% CI -0.6 to 1.5$)$ and 0.7 (95\% CI -0.1 to 1.5 ) respectively] (Table 3, model 1, and Fig. 1a). Further adjustments for prior CVD, hypertension, WHR, total/HDL cholesterol, triglycerides, educational level, physical activity, smoking, aMED score and the use of antihypertensive and 
Table 1. Clinical characteristics of the study population according to the presence of clinically important depressive symptoms (CES-D $\geqslant 16)$

\begin{tabular}{|c|c|c|}
\hline & $\begin{array}{l}\text { CES-D score }<16 \\
n=430(87.2 \%)\end{array}$ & $\begin{array}{l}\text { CES-D score } \geqslant 16 \\
n=63(12.8 \%)\end{array}$ \\
\hline \multicolumn{3}{|l|}{ Demographics } \\
\hline Age (years) & $68.0(64.0-74.0)$ & $71.0(66.0-75.0)$ \\
\hline Women & 48.1 & 61.9 \\
\hline \multicolumn{3}{|l|}{ Smoking status } \\
\hline Non-smoker & 20.9 & 36.5 \\
\hline Former smoker & 63.2 & 49.2 \\
\hline Current smoker & 15.9 & 14.3 \\
\hline Low education level & 21.4 & 36.5 \\
\hline Physical activity (MET h/week) & $80(47-130)$ & $56(25-104)$ \\
\hline aMED score & $4.0(3.0-5.0)$ & $4.0(3.0-5.0)$ \\
\hline \multicolumn{3}{|l|}{ Glucose metabolism status } \\
\hline Normal glucose metabolism & 49.8 & 30.2 \\
\hline Impaired glucose metabolism & 31.6 & 38.1 \\
\hline Type 2 diabetes mellitus & 18.6 & 30.1 \\
\hline Prior cardiovascular disease & 46.3 & 52.5 \\
\hline \multicolumn{3}{|l|}{ Metabolic variables } \\
\hline Body mass index $\left(\mathrm{kg} / \mathrm{m}^{2}\right)$ & $26.6(24.5-29.3)$ & $28.9(25.3-31.4)$ \\
\hline Waist-to-hip ratio & $0.93(0.86-0.99)$ & $0.94(0.86-0.99)$ \\
\hline Systolic blood pressure $(\mathrm{mmHg})$ & $142(127-156)$ & $144(130-159)$ \\
\hline Diastolic blood pressure (mmHg) & $83(76-90)$ & $83(72-92)$ \\
\hline Hypertension & 67.9 & 71.4 \\
\hline $\mathrm{HbA} 1 \mathrm{c}(\mathrm{mmol} / \mathrm{mol})$ & $39.9(37.7-44.3)$ & $41.0(37.7-47.0)$ \\
\hline $\mathrm{HbA1c}(\%)$ & $5.8(5.6-6.2)$ & $5.9(5.6-6.5)$ \\
\hline Total cholesterol (mmol/l) & $5.7(5.0-6.3)$ & $6.0(4.9-6.7)$ \\
\hline LDL cholesterol (mmol/l) & $3.6(3.0-4.2)$ & $3.8(2.9-4.4)$ \\
\hline HDL cholesterol (mmol/l) & $1.4(1.1-1.7)$ & $1.3(1.0-1.5)$ \\
\hline Triglycerides $(\mathrm{mmol} / \mathrm{l})$ & $1.3(1.0-1.7)$ & $1.4(1.2-2.1)$ \\
\hline Albuminuria (albumin/creatinine ratio $>2 \mathrm{mg} / \mathrm{mmol}$ ) & 14.7 & 9.5 \\
\hline $\operatorname{eGFR}\left(\mathrm{ml} / \mathrm{min} / 1.73 \mathrm{~m}^{2}\right)$ & $77.4(70.0-89.5)$ & $76(64.8-89.7)$ \\
\hline \multicolumn{3}{|l|}{ Medication } \\
\hline Lipid-lowering medication & 15.6 & 17.5 \\
\hline Antihypertensive medication & 64.6 & 44.4 \\
\hline Antidepressive medication & 1.9 & 3.2 \\
\hline
\end{tabular}

CES-D, Center for Epidemiologic Studies Depression Scale; MET, metabolic equivalent of task; aMED, alternative Mediterranean diet; HbA1c, glycosylated haemoglobin; LDL, low density lipoprotein; HDL, high density lipoprotein; eGFR, estimated glomerular filtration rate.

Data are presented as percentage or median (interquartile range).

lipid-lowering medication, and metformin did not materially alter these results (models 2-4). Furthermore, the associations for the total ED score and the OxS circulating biomarker $Z$ score did not materially change if model 1 was additionally adjusted for each of the other biomarkers scores (models 5-7). When we adjusted the LGI circulating biomarker $Z$ score for the ED circulating biomarker $Z$ score, the regression coefficient changed from 0.4 (95\% CI -0.6 to 1.5$)$ to -0.1 (95\% CI -1.2 to 1.1 ) (model 7). This change in the point estimate should nevertheless be interpreted with caution, as the CI of both point estimates incorporates the value zero.

\section{Association between ED, LGI and OxS and clinically important depressive symptoms}

The results of the logistic regression analyses (CES-D expressed on a dichotomous scale) show that, after adjustment for age, sex and glucose metabolism status, a 1 s.D. increase in the total ED score was associated with clinically important depressive symptoms with an odds ratio (OR) of 1.9 (95\% CI 0.9-3.8) (Table 4, model 1). The LGI and OxS circulating biomarker $Z$ scores were associated with clinically important depressive symptoms with an OR of 1.3 (95\% CI 0.8-2.0) and $1.2 \quad(95 \% \quad \mathrm{CI} \quad 0.8-1.8)$ respectively 
Table 2. Markers of endothelial dysfunction (ED), low-grade inflammation (LGI) and oxidative stress (OxS) according to the presence of clinically important depressive symptoms (CES-D $\geqslant 16)$

\begin{tabular}{|c|c|c|}
\hline & $\begin{array}{l}\text { CES-D score }<16 \\
n=430(87.2 \%)\end{array}$ & $\begin{array}{l}\text { CES-D score } \geqslant 16 \\
n=63(12.8 \%)\end{array}$ \\
\hline \multicolumn{3}{|l|}{ ED } \\
\hline Total ED score (S.D.) & $-0.09(-0.42$ to 0.29$)$ & $0.15(-0.19$ to 0.45$)$ \\
\hline FMD Z score (S.D.) & $0.09(-0.56$ to 0.71$)$ & $0.50(-0.18$ to 0.91$)$ \\
\hline Absolute change in diameter ( $\mathrm{mm})$ & $0.17(0.08$ to 0.27$)$ & $0.10(0.04$ to 0.21$)$ \\
\hline Percentage change in diameter & $3.7(1.5$ to 5.9$)$ & $2.5(0.7$ to 4.8$)$ \\
\hline Baseline diameter (mm) & 4.62 (4.13 to 5.08$)$ & 4.59 (3.97 to 4.89$)$ \\
\hline Flow increase after cuff release (\%) & 82 (58 to 107$)$ & 91 (56 to 118$)$ \\
\hline $\mathrm{NMD}(\mathrm{mm})$ & $0.42(0.30$ to 0.56$)$ & 0.39 (0.27 to 0.52$)$ \\
\hline ED circulating biomarker $Z$ score (S.D.) & $-0.15(-0.44$ to 0.30$)$ & $0.04(-0.32$ to 0.52$)$ \\
\hline sVCAM-1 $(\mu \mathrm{g} / \mathrm{l})$ & $390.6(342.3$ to 446.4$)$ & 427 (350.4 to 486.1$)$ \\
\hline sE-selectin $(\mu \mathrm{g} / \mathrm{l})$ & $17.9(13.9$ to 23.4$)$ & $16.6(12.2$ to 21.3$)$ \\
\hline sTM $(\mu \mathrm{g} / 1)$ & $3.4(2.9$ to 4.0$)$ & $3.5(3.1$ to 4.1$)$ \\
\hline sICAM-1 ( $\mu \mathrm{g} / \mathrm{l})$ & 248.8 (219.0 to 286.3 ) & $257.9(223.9$ to 294.4$)$ \\
\hline vWF (\%) & 146.5 (114.9 to 180.0$)$ & $177.4(135.2$ to 212.0$)$ \\
\hline \multicolumn{3}{|l|}{ LGI } \\
\hline LGI circulating biomarker $Z$ score (S.D.) & $-0.08(-0.43$ to 0.26$)$ & $0.10(-0.34$ to 0.41$)$ \\
\hline CRP (mg/l) & $2.2(1.2$ to 4.6$)$ & $2.7(1.2$ to 5.0$)$ \\
\hline SAA $(\mathrm{mg} / \mathrm{l})$ & 1.7 (1.0 to 3.2$)$ & $2.0(1.4$ to 3.0$)$ \\
\hline IL-6 (ng/l) & $1.5(1.1$ to 2.4$)$ & $1.8(1.2$ to 2.6$)$ \\
\hline IL-8 (ng/l) & $15.0(11.5$ to 19.6$)$ & 15.5 (12.2 to 19.6$)$ \\
\hline TNF- $\alpha(n g / l)$ & $8.4(7.1$ to 10.0$)$ & $8.9(7.8$ to 10.3$)$ \\
\hline $\mathrm{MPO}(\mu \mathrm{g} / \mathrm{l})$ & $55.2(46.9$ to 65.2$)$ & $57.3(48.8$ to 67.6$)$ \\
\hline sICAM-1 $(\mu \mathrm{g} / \mathrm{l})$ & 248.8 (219.0 to 286.3 ) & $257.9(223.9$ to 294.4$)$ \\
\hline \multicolumn{3}{|l|}{ OxS } \\
\hline OxS circulating biomarker $Z$ score (S.D.) & $-0.06(-0.48$ to 0.37$)$ & $0.18(-0.46$ to 0.64$)$ \\
\hline oxLDL (U/l) & $62.1(53.7$ to 73.1$)$ & $66.6(53.3$ to 80.8$)$ \\
\hline $\mathrm{MPO}(\mu \mathrm{g} / \mathrm{l})$ & 55.2 (46.9 to 65.2$)$ & $57.3(48.8$ to 67.6$)$ \\
\hline
\end{tabular}

CES-D, Center for Epidemiologic Studies Depression Scale; FMD, flow-mediated dilatation; NMD, nitroglycerin-mediated dilatation; sVCAM-1, soluble vascular adhesion molecule 1; sE-selectin, soluble endothelial selectin; sTM, soluble thrombomodulin; sICAM-1, soluble intracellular adhesion molecule 1; vWF, von Willebrand factor; CRP, C-reactive protein; SAA, serum amyloid A; IL-6, interleukin 6; IL-8, interleukin 8; TNF- $\alpha$, tumour necrosis factor $\alpha$; MPO, myeloperoxidase; oxLDL, oxidized low density lipoprotein; S.D., standard deviation.

Data are presented as medians (interquartile range).

(Table 4, model 1). Further adjustments for prior CVD, hypertension, WHR, total/HDL cholesterol, triglycerides, educational level, physical activity, smoking, aMED score and the use of antihypertensive and lipid-lowering medication, and metformin did not materially change these results (models 2-4). If we adjusted the total ED score for the LGI circulating biomarker $Z$ score, the OR changed from 1.9 (95\% CI $0.9-3.8)$ to 2.4 (95\% CI 1.1-5.4) (model 5). If we adjusted the results of the LGI and OxS circulating biomarker $Z$ scores for each of the other biomarker scores, the results did not materially change (models $5-7$ ).

\section{Additional analyses}

Analyses of the associations between the individual elements of the ED, LGI and OxS circulating biomarker
$Z$ scores and the CES-D score on a continuous scale show that all individual circulating biomarkers, except sE-selectin and MPO, were associated with the CES-D score (statistically significant for sVCAM-1, vWF and oxLDL; see Fig. $1 b-d$ ). Previous studies (Ridker et al. 2000; Brevetti et al. 2001) have suggested that sICAM-1 may be a marker of both ED and LGI. When the analyses were repeated with sICAM-1 left out of either the ED or the LGI circulating biomarker $Z$ score, the results did not materially change (data not shown). In addition, we considered MPO as a marker of both LGI and OxS (Brennan et al. 2003; van der Zwan et al. 2010b). When the analyses were repeated leaving MPO out of the LGI circulating biomarker $\mathrm{Z}$ score, the results did not materially change (data not shown). Finally, it is unclear whether a high or a 
Table 3. Associations of endothelial dysfunction (ED), low-grade inflammation (LGI) and oxidative stress (OxS) with depressive symptoms (continuous CES-D score)

\begin{tabular}{|c|c|c|c|c|c|c|}
\hline \multirow[b]{2}{*}{ Model } & \multirow[b]{2}{*}{ Adjustments } & \multicolumn{3}{|l|}{$\mathrm{ED}$} & \multirow{2}{*}{$\begin{array}{l}\text { LGI } \\
\text { LGI circulating } \\
\text { biomarker Z score }\end{array}$} & \multirow{2}{*}{$\begin{array}{l}\text { OxS } \\
\text { OxS circulating } \\
\text { biomarker } Z \text { score }\end{array}$} \\
\hline & & Total ED score & FMD Z score $^{\mathrm{a}}$ & $\begin{array}{l}\text { ED circulating } \\
\text { biomarker } Z \text { score }\end{array}$ & & \\
\hline 1 & Age, sex, glucose metabolism status & $1.9(0.7-3.1)$ & 0.7 (0.1 to 1.4$)$ & $1.3(0.2$ to 2.5$)$ & $0.4(-0.6$ to 1.5$)$ & $0.7(-0.1$ to 1.5$)$ \\
\hline 2 & $\begin{array}{l}\text { Model } 1+\text { prior CVD, hypertension, WHR, } \\
\text { triglycerides, total/HDL cholesterol }\end{array}$ & $1.8(0.6-3.0)$ & $0.7(0.05$ to 1.3$)$ & $1.0(0.1$ to 1.9$)$ & $0.3(-0.8$ to 1.3$)$ & $0.6(-0.3 \text { to } 1.4)^{\mathrm{b}}$ \\
\hline 3 & $\begin{array}{l}\text { Model } 1+\text { education level, physical activity, } \\
\text { smoking status, aMED score }\end{array}$ & $1.8(0.6-3.0)$ & $0.6(-0.01$ to 1.3$)$ & 1.1 (0.2 to 2.1$)$ & $0.3(-0.8$ to 1.3$)$ & $0.6(-0.2$ to 1.4$)$ \\
\hline 4 & $\begin{array}{l}\text { Model } 1+\text { antihypertensive and lipid-lowering } \\
\text { medication, metformin }\end{array}$ & $1.9(0.7-3.1)$ & 0.7 (0.1 to 1.4$)$ & 1.3 (0.2 to 2.5$)$ & $0.4(-0.6$ to 1.5$)$ & $0.7(-0.2$ to 1.5$)$ \\
\hline 5 & Model 1+LGI Z score & $2.1(0.9-3.3)$ & 0.7 (0.1 to 1.4$)$ & 1.3 (0.2 to 2.3$)$ & - & $0.6(-0.2$ to 1.5$)$ \\
\hline 6 & Model 1+OxS Z score & $1.9(0.7-3.1)$ & $0.7(0.1$ to 1.3$)$ & $1.2(-0.1$ to 2.4$)$ & $0.2(-0.8$ to 1.2$)$ & - \\
\hline 7 & Model 1+ED Z score & - & - & - & $-0.1(-1.2$ to 1.1$)$ & $0.4(-0.4$ to 1.3$)$ \\
\hline
\end{tabular}

CES-D, Center for Epidemiologic Studies Depression Scale; FMD, flow-mediated dilatation; CVD, cardiovascular disease; WHR, waist-to-hip ratio; HDL, high density lipoprotein; aMED, alternative Mediterranean diet.

Values are given as regression coefficients (95\% confidence interval) expressed per standard deviation increase in total ED score $(n=357)$, FMD $Z$ score $(n=357)$, ED circulating biomarker $Z$ score $(n=493)$, LGI circulating biomarker $Z$ score $(n=493)$ and $(\mathrm{OxS})$ circulating biomarker $Z$ score $(n=493)$ on the CES-D.

${ }^{a}$ The FMD $Z$ score was reversed, that is multiplied by -1 ; higher values indicating worse endothelial function. In all analyses the FMD $Z$ score was adjusted for baseline diameter, flow increase after cuff release and nitroglycerin-mediated dilatation (NMD).

${ }^{\mathrm{b}}$ The OxS circulating biomarker $Z$ score was not adjusted for triglycerides and total/HDL cholesterol as this was considered an overadjustment, as oxidized low density lipoprotein (oxLDL) is a component of the OxS circulating biomarker $Z$ score. 
(a)

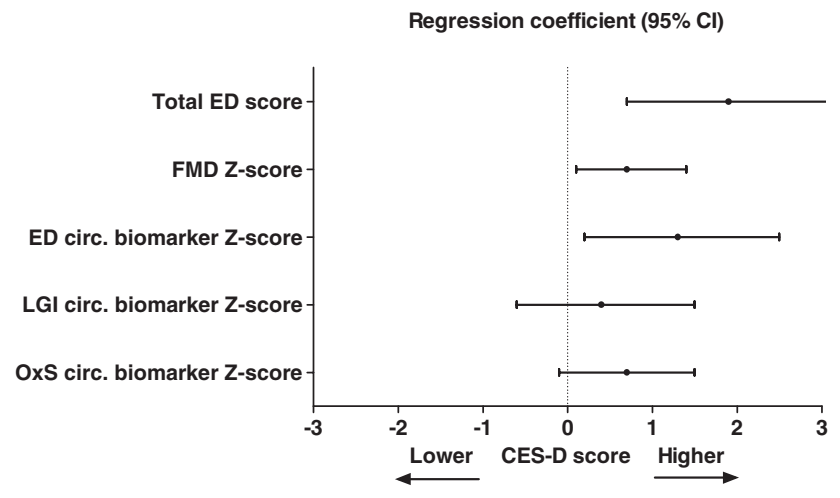

(c)

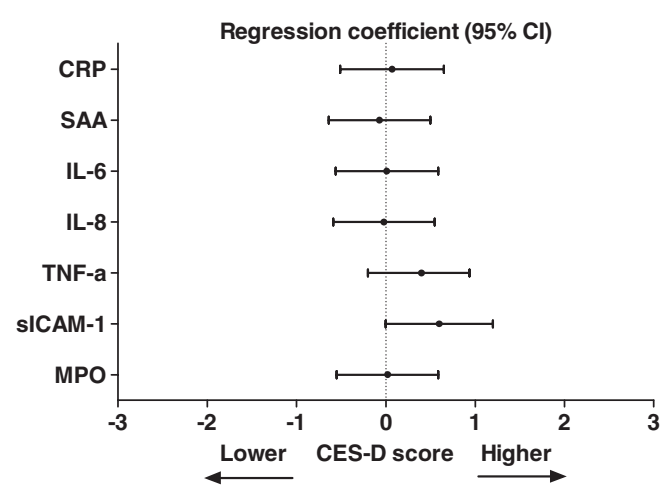

(b)

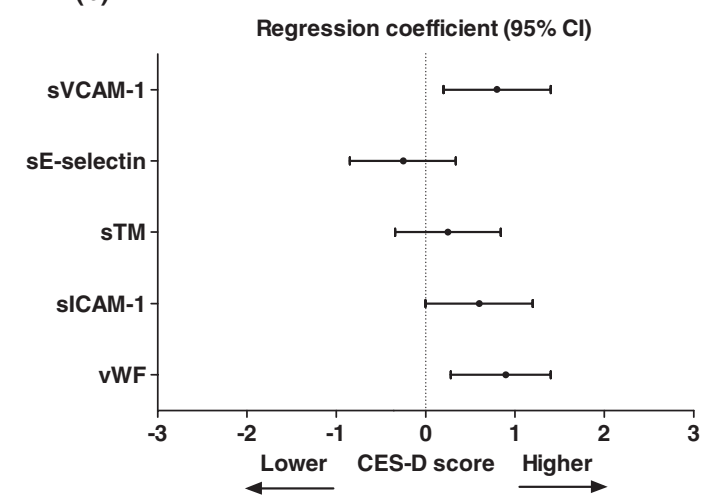

(d)

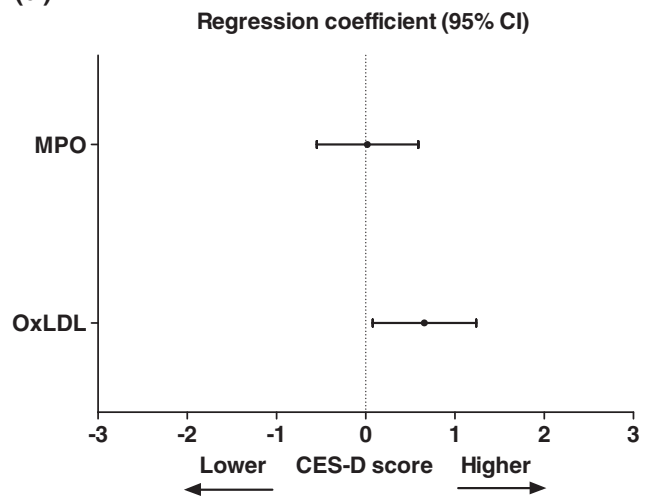

Fig. 1. Associations of endothelial dysfunction (ED), low-grade inflammation (LGI) and oxidative stress (OxS) with depressive symptoms [continuous Center for Epidemiologic Studies Depression Scale (CES-D) score]. (a) Regression coefficients [95\% confidence intervals (CIs)] expressed per standard deviation (s.D.) increase in total ED score, flow-mediated dilatation (FMD) $Z$ score and ED, LGI and OxS circulating biomarker Z scores. The FMD Z score was reversed, that is multiplied by -1 , higher values indicating worse function. Also shown are individual circulating biomarkers (per S.D.) of (b) ED, (c) LGI and (d) OxS. All results are adjusted for age, sex and glucose metabolism status. sVCAM-1, Soluble vascular cell adhesion molecule 1; sE-selectin, soluble endothelial selectin; sTM, soluble thrombomodulin; sICAM-1, soluble intercellular adhesion molecule 1; vWF, von Willebrand factor; CRP, C-reactive protein; SAA, serum amyloid A; IL-6, interleukin 6; IL-8, interleukin 8 ; TNF- $\alpha$, tumour necrosis factor $\alpha$; MPO, myeloperoxidase; oxLDL, oxidized low density lipoprotein.

low concentration of sTM reflects ED (Wu, 2003). The results did not materially change when we performed the analysis with either the reversed value of sTM or leaving sTM out of the total ED score (data not shown).

To determine whether the association between FMD and depression was due to impaired ED or smooth muscle cell function (Henry et al. 2004), we repeated the analyses with endothelium-independent NMD as the primary determinant. These analyses showed that NMD was not associated with (clinically relevant) depressive symptoms (data not shown).

The associations between ED, LGI and OxS on the one hand and depressive symptoms on the other may differ according to sex or glucose metabolism status (Musselman et al. 2003; Krishnan \& Nestler, 2010). Overall, we found no such interactions ( $p$ interaction $>0.10$ ), except that stratified analysis showed a stronger association between the LGI biomarker
$Z$ score and depressive symptoms in persons with impaired glucose metabolism compared to persons with normal glucose metabolism ( $p$ interaction $=0.03$ ). In addition, the association between the OxS biomarker $Z$ score and depressive symptoms was stronger in persons with impaired glucose metabolism ( $p$ interaction $=$ 0.01 ) and in persons with type 2 diabetes ( $p$ interaction $=0.07$ ), compared to persons with normal glucose metabolism (data not shown).

When the statistical analyses were repeated on those participants $(n=357)$ who had full data on both circulating biomarkers and FMD, the results did not materially change (data not shown). Finally, when we repeated the analyses with clinically relevant depressive symptoms defined as a CES-D score $\geqslant 16$ and/or medication use for a depressive disorder $(n=$ $67,13.6 \%$ ) as the outcome variable instead of clinically relevant depressive symptoms only (CES-D $\geqslant 16$ ), the results did not materially change (data not shown). 
Table 4. Associations of endothelial dysfunction (ED), low-grade inflammation (LGI) and oxidative stress (OxS) with clinically relevant depression (CES-D $\geqslant 16$ )

\begin{tabular}{|c|c|c|c|c|c|c|}
\hline \multirow[b]{2}{*}{ Model } & \multirow[b]{2}{*}{ Adjustments } & \multicolumn{3}{|l|}{ ED } & \multirow{2}{*}{$\begin{array}{l}\text { LGI } \\
\text { LGI circulating } \\
\text { biomarker } Z \text { score }\end{array}$} & \multirow{2}{*}{$\begin{array}{l}\text { OxS } \\
\text { OxS circulating } \\
\text { biomarker } Z \text { score }\end{array}$} \\
\hline & & Total ED score & FMD Z score ${ }^{\mathrm{a}}$ & $\begin{array}{l}\text { ED circulating } \\
\text { biomarker } Z \text { score }\end{array}$ & & \\
\hline 1 & Age, sex, glucose metabolism status & $1.9(0.9-3.8)$ & $1.4(0.9-2.4)$ & $1.6(1.0-2.3)$ & $1.3(0.8-2.0)$ & $1.2(0.8-1.8)$ \\
\hline 2 & $\begin{array}{l}\text { Model } 1+\text { prior CVD, hypertension, WHR, } \\
\text { triglycerides, total/HDL cholesterol }\end{array}$ & $1.8(0.9-3.7)$ & $1.5(0.9-2.5)$ & $1.5(1.0-2.3)$ & $1.3(0.8-2.0)$ & $1.2(0.8-1.7)^{\mathrm{b}}$ \\
\hline 3 & $\begin{array}{l}\text { Model } 1+\text { education level, physical activity, } \\
\text { smoking status, aMED score }\end{array}$ & $2.1(1.0-4.1)$ & $1.5(0.9-2.5)$ & $1.7(1.1-2.5)$ & $1.3(0.8-2.1)$ & $1.2(0.8-1.8)$ \\
\hline 4 & $\begin{array}{l}\text { Model } 1+\text { antihypertensive and lipid-lowering } \\
\text { medication, metformin }\end{array}$ & $2.0(1.0-4.0)$ & $1.5(0.9-2.5)$ & $1.6(1.1-2.4)$ & $1.3(0.8-2.0)$ & $1.2(0.8-1.8)$ \\
\hline 5 & Model 1+LGI Z score & $2.4(1.1-5.4)$ & $1.4(0.9-2.4)$ & $1.6(1.0-2.4)$ & - & $1.2(0.8-1.8)$ \\
\hline 6 & Model 1+OxS Z score & $2.0(1.0-4.2)$ & $1.4(0.9-2.4)$ & $1.5(1.0-2.3)$ & $1.3(0.8-2.0)$ & - \\
\hline 7 & Model 1+ED Z score & & - & - & $1.0(0.6-1.7)$ & $1.1(0.7-1.7)$ \\
\hline
\end{tabular}

CES-D, Center for Epidemiologic Studies Depression Scale; FMD, flow-mediated dilatation; CVD, cardiovascular disease; WHR, waist-to-hip ratio; HDL, high density lipoprotein; aMED, alternative Mediterranean diet.

Values are given as odds ratios (95\% confidence interval) expressed per standard deviation increase in total ED score ( $n=357)$, FMD Z score ( $n=357)$, ED circulating biomarker $Z$ score $(n=493)$, LGI circulating biomarker $Z$ score $(n=493)$ and OxS circulating biomarker $Z$ score $(n=493)$. Sixty-three $(12.8 \%)$ of the study participants had clinically relevant depressive symptoms (CES-D score $\geqslant 16$ ).

a The FMD $Z$ score was reversed, that is multiplied by -1 , higher values indicating worse endothelial function. In all analyses the FMD $Z$ score was adjusted for baseline diameter, flow increase after cuff release and nitroglycerin-mediated dilatation (NMD).

${ }^{\mathrm{b}}$ The OxS circulating biomarker $Z$ score was not adjusted for triglycerides and total/HDL cholesterol as this was considered an overadjustment, as oxidized low density lipoprotein (oxLDL) is a component of the OxS circulating biomarker $Z$ score. 


\section{Discussion}

The present investigation is the first population-based study that simultaneously assessed the association of ED, LGI and OxS with depressive symptoms in one study. The study had three main findings. First, ED, as quantified by FMD and circulating biomarkers, was associated with a higher level of (clinically relevant) depressive symptoms. This association was independent of age, sex, diabetes, CVD risk factors, physical activity, dietary intake and education level. Second, circulating biomarkers for LGI and OxS were not statistically significantly associated with depressive symptoms. Third, adjustments for LGI or OxS did not affect the association between ED and depressive symptoms, which suggests that ED is associated with depressive symptoms/depression, independently of LGI and OxS.

A key concept underlying this study is that ED, LGI and OxS are generalized phenomena and that each of these phenomena represents either directly or indirectly ED, LGI or OxS in the brain. Currently, literature on this topic is limited. Nevertheless, it can be hypothesized that the impaired cerebral circulatory function seen in depression, as determined by transcranial Doppler ultrasonography (Direk et al. 2012), may be the consequence of decreased endotheliumdependent vasodilation. In addition, it has been shown that the process of neurogenesis (i.e. the process by which neural progenitors divide and form new neurons and neuronal networks) is disturbed in depression (Belmaker \& Agam, 2008; Krishnan \& Nestler, 2010) and that this disturbance may, at least partially, be the consequence of ED (Shen et al. 2004; Zhao et al. 2008).

On aggregate, most studies thus far (Lesperance et al. 2004; Empana et al. 2005; Sherwood et al. 2005; Rybakowski et al. 2006; Narita et al. 2007; Pizzi et al. 2008; Schott et al. 2009; Cooper et al. 2010; Paranthaman et al. 2010) have shown that ED and depression seem to be associated. However, conflicting results in the literature do exist. For instance, Thomas et al. (2007) did not observe any association between ED and depression in a small and select population of patients diagnosed with major depressive disorder. In their study, however, it is unclear how potential confounders were taken into account (e.g. antiinflammatory medication). An alternative explanation for the reported heterogeneous results may lie in the fact that endothelial function can be defined in many ways as its functions are multi-dimensional and heterogeneous (Aird, 2007a,b). This is exemplified by Paranthaman et al. (2010) who did report an association between ED and depression but quantified ED as the vasodilatory response to acetylcholine of biopsied small gluteal arteries. Do et al. (2010) quantified ED by multiple circulating biomarkers and reported an association between ED and, specifically, hopelessness, which reflects, as argued by the authors, a distinct and unique component of depression only. Pizzi et al. (2008) quantified ED by FMD and showed an association between FMD and depressive symptoms; however, in their study no adjustments were made for important confounders, such as physical activity and dietary habits.

The present investigation extends previous observations because of its population-based design, the extensive assessment of ED, LGI and OxS, and the detailed clinical characterization of its participants, which enabled us to adjust for a series of potential confounders.

Apart from a causal association between ED and depression, other underlying mechanisms might explain the observed association. First, ED is involved in the pathophysiology of CVD (Aird, 2007a,b) and depression is common in persons with CVD (Belmaker \& Agam, 2008). Therefore, it is possible that ED might lead to depression through the development of CVD. However, the association of ED with depressive symptoms remained after adjustment for prior CVD and several CVD risk factors. Second, depressive symptoms by themselves might initiate or promote ED (reverse causality), as depressive symptoms/depression are associated with unfavourable lifestyle habits, such as physical inactivity, unhealthy dietary habits, smoking and obesity, which are by themselves associated with ED. The association between ED and depressive symptoms, however, remained after adjustment for unfavourable lifestyle habits. Third, other mechanisms may underlie both ED and depression. For instance, abnormal HPA axis function (Broadley et al. 2006) and deficits in omega-3 fatty acids (Parker et al. 2006) have been associated with both ED and depression. In the current study, cortisol and omega-3 fatty acids levels were not available and this issue needs further study. Fourth, ED, LGI and OxS are, from a biological point of view, closely linked and these concepts are difficult to separate (Stehouwer et al. 2002). Therefore, any association of ED with depressive symptoms may be confounded by LGI and/ or OxS. However, when we adjusted the association between ED and depression for LGI or OxS, ED and depression remained associated. This suggests that ED may affect the brain through a pathway independent of LGI and OxS. For instance, it might be possible that ED directly affects the process of neurogenesis (Shen et al. 2004; Zhao et al. 2008), or ED might directly impair cerebral circulatory function (Lemke et al. 2010).

In our study, the LGI and the OxS Z scores were associated with clinically relevant depressive symptoms, 
with effect sizes comparable to the results reported in the literature (Ford \& Erlinger, 2004; Lesperance et al. 2004; Panagiotakos et al. 2004; Empana et al. 2005; Forlenza \& Miller, 2006; Miller et al. 2009). However, in our study these associations did not reach statistical significance. We cannot exclude the possibility that this may be due to a lack of statistical power. Indeed, a meta-analysis by Howren et al. (2009) did show a significant association between different markers of LGI (CRP, IL-1 and IL-6) and depression/depressive symptoms. With regard to OxS in particular, we only assessed two biomarkers (MPO and oxLDL); there is also an ongoing debate how OxS could best be defined.

We explored whether the relationship between ED, LGI and OxS and depression differed according to glucose metabolism status. Our findings show that the association between the LGI biomarker $Z$ score and depressive symptoms was stronger in persons with impaired glucose metabolism than in those with normal glucose metabolism. A plausible underlying pathobiological explanation for this observation is lacking. In addition, our results show that the association between the OxS biomarker $Z$ score and depressive symptoms was stronger in persons with impaired glucose metabolism and in those with type 2 diabetes. We could speculate that the hyperglycaemic state may indeed amplify the effect of OxS on depressive symptoms/depression, even though the hyperglycaemic state itself enhances OxS. Fully stratified analyses, however, were hampered by lack of power and further studies of this issue are needed.

Our study has some limitations. First, the crosssectional design of our study precludes any conclusions about causality and it is possible that other factors may explain the association between ED and depressive symptoms/depression. Nevertheless, in our study the association between ED and depressive symptoms remained even after adjustment for glucose metabolism status, CVD, obesity, physical inactivity, poor dietary habits, smoking and education level. Second, the construction of the $Z$ scores assumes that its components are equally important in the pathobiology of depression, which is not necessarily true. This might have caused us to underestimate the reported associations. However, the use of the composite $Z$ score has the important merit of statistical efficiency. Third, a relatively large number of statistical tests were performed (we tested three ED scores and one each of LGI and OxS); however, the associations between ED and depressive symptoms were consistent across the different ED scores. It is therefore unlikely that these findings result by chance. Fourth, data were obtained in an elderly white population and it therefore remains to be established whether these results can be generalized to other populations.
In conclusion, the present population-based study shows that ED, quantified by an array of peripherally circulating biomarkers and FMD, is associated with depressive symptoms. Our data thereby support the hypothesis that ED plays an important role in the pathobiology of depression.

\section{Acknowledgements}

The Hoorn Study has been supported over the years by the VU University Medical Centre, and by the Dutch Diabetes Research Foundation, the Dutch Organization for Scientific Research, The Netherlands Heart Foundation and the Health Research and Development Council of The Netherlands.

\section{Declaration of Interest}

None.

\section{References}

Aird WC (2007a). Phenotypic heterogeneity of the endothelium: I. Structure, function, and mechanisms. Circulation Research 100, 158-173.

Aird WC (2007b). Phenotypic heterogeneity of the endothelium: II. Representative vascular beds. Circulation Research 100, 174-190.

Beekman AT, Deeg DJ, Van Limbeek J, Braam AW, De Vries MZ, Van Tilburg W (1997). Criterion validity of the Center for Epidemiologic Studies Depression scale (CES-D): results from a community-based sample of older subjects in The Netherlands. Psychological Medicine 27, 231-235.

Belmaker RH, Agam G (2008). Major depressive disorder. New England Journal of Medicine 358, 55-68.

Brennan ML, Penn MS, Van Lente F, Nambi V, Shishehbor MH, Aviles RJ, Goormastic M, Pepoy ML, McErlean ES, Topol EJ, Nissen SE, Hazen SL (2003). Prognostic value of myeloperoxidase in patients with chest pain. New England Journal of Medicine 349, 1595-1604.

Brevetti G, Martone VD, de Cristofaro T, Corrado S, Silvestro A, Di Donato AM, Bucur R, Scopacasa F (2001). High levels of adhesion molecules are associated with impaired endothelium-dependent vasodilation in patients with peripheral arterial disease. Thrombosis and Haemostasis 85, 63-66.

Broadley AJ, Korszun A, Abdelaal E, Moskvina V, Deanfield J, Jones CJ, Frenneaux MP (2006). Metyrapone improves endothelial dysfunction in patients with treated depression. Journal of the American College of Cardiology 48, 170-175.

Cooper DC, Milic MS, Tafur JR, Mills PJ, Bardwell WA, Ziegler MG, Dimsdale JE (2010). Adverse impact of mood on flow-mediated dilation. Psychosomatic Medicine 72, 122-127.

Corretti MC, Anderson TJ, Benjamin EJ, Celermajer D, Charbonneau F, Creager MA, Deanfield J, Drexler H, 
Gerhard-Herman M, Herrington D, Vallance P, Vita J, Vogel R (2002). Guidelines for the ultrasound assessment of endothelial-dependent flow-mediated vasodilation of the brachial artery: a report of the International Brachial Artery Reactivity Task Force. Journal of the American College of Cardiology 39, 257-265.

Dantzer R, O'Connor JC, Freund GG, Johnson RW, Kelley KW (2008). From inflammation to sickness and depression: when the immune system subjugates the brain. Nature Reviews Neuroscience 9, 46-56.

Direk N, Koudstaal PJ, Hofman A, Ikram MA, Hoogendijk WJ, Tiemeier H (2012). Cerebral hemodynamics and incident depression: the Rotterdam Study. Biological Psychiatry 72, 318-323.

Do DP, Dowd JB, Ranjit N, House JS, Kaplan GA (2010). Hopelessness, depression, and early markers of endothelial dysfunction in U.S. adults. Psychosomatic Medicine 72, 613-619.

Du H, van der A DL, van Bakel MM, van der Kallen CJ, Blaak EE, van Greevenbroek MM, Jansen EH, Nijpels G, Stehouwer CD, Dekker JM, Feskens EJ (2008).

Glycemic index and glycemic load in relation to food and nutrient intake and metabolic risk factors in a Dutch population. American Journal of Clinical Nutrition 87, 655-661.

Elovainio M, Aalto AM, Kivimaki M, Pirkola S, Sundvall J, Lonnqvist J, Reunanen A (2009). Depression and C-reactive protein: population-based Health 2000 Study. Psychosomatic Medicine 71, 423-430.

Empana JP, Sykes DH, Luc G, Juhan-Vague I, Arveiler D, Ferrieres J, Amouyel P, Bingham A, Montaye M, Ruidavets JB, Haas B, Evans A, Jouven X, Ducimetiere P (2005). Contributions of depressive mood and circulating inflammatory markers to coronary heart disease in healthy European men: the Prospective Epidemiological Study of Myocardial Infarction (PRIME). Circulation 111, 2299-2305.

Ford DE, Erlinger TP (2004). Depression and C-reactive protein in US adults: data from the Third National Health and Nutrition Examination Survey. Archives of Internal Medicine 164, 1010-1014.

Forlenza MJ, Miller GE (2006). Increased serum levels of 8-hydroxy-2'-deoxyguanosine in clinical depression. Psychosomatic Medicine 68, 1-7.

Fung TT, McCullough ML, Newby PK, Manson JE, Meigs JB, Rifai N, Willett WC, Hu FB (2005). Diet-quality scores and plasma concentrations of markers of inflammation and endothelial dysfunction. American Journal of Clinical Nutrition 82, 163-173.

Henry RM, Ferreira I, Kostense PJ, Dekker JM, Nijpels G, Heine RJ, Kamp O, Bouter LM, Stehouwer CD (2004).

Type 2 diabetes is associated with impaired endothelium-dependent, flow-mediated dilation, but impaired glucose metabolism is not-the Hoorn Study. Atherosclerosis 174, 49-56.

Henry RM, Kostense PJ, Spijkerman AM, Dekker JM, Nijpels G, Heine RJ, Kamp O, Westerhof N, Bouter LM, Stehouwer CD (2003). Arterial stiffness increases with deteriorating glucose tolerance status: the Hoorn Study. Circulation 107, 2089-2095.
Howren MB, Lamkin DM, Suls J (2009). Associations of depression with C-reactive protein, IL-1, and IL-6: a meta-analysis. Psychosomatic Medicine 71, 171-186.

Jager A, van Hinsbergh VW, Kostense PJ, Emeis JJ, Yudkin JS, Nijpels G, Dekker JM, Heine RJ, Bouter LM, Stehouwer CD (1999). von Willebrand factor, C-reactive protein, and 5-year mortality in diabetic and nondiabetic subjects: the Hoorn Study. Arteriosclerosis, Thrombosis, and Vascular Biology 19, 3071-3078.

Krishnan V, Nestler EJ (2010). Linking molecules to mood: new insight into the biology of depression. American Journal of Psychiatry 167, 1305-1320.

Kupper N, Gidron Y, Winter J, Denollet J (2009). Association between type $\mathrm{D}$ personality, depression, and oxidative stress in patients with chronic heart failure. Psychosomatic Medicine 71, 973-980.

Lemke H, de Castro AG, Schlattmann P, Heuser I, Neu P (2010). Cerebrovascular reactivity over time-course - from major depressive episode to remission. Journal of Psychiatric Research 44, 132-136.

Lesperance F, Frasure-Smith N, Theroux P, Irwin M (2004). The association between major depression and levels of soluble intercellular adhesion molecule 1, interleukin-6, and C-reactive protein in patients with recent acute coronary syndromes. American Journal of Psychiatry 161, 271-277.

Levey AS, Coresh J, Greene T, Marsh J, Stevens LA, Kusek JW, Van Lente F (2007). Expressing the Modification of Diet in Renal Disease Study equation for estimating glomerular filtration rate with standardized serum creatinine values. Clinical Chemistry 53, 766-772.

Maes M, Galecki P, Chang YS, Berk M (2011). A review on the oxidative and nitrosative stress (O\&NS) pathways in major depression and their possible contribution to the (neuro)degenerative processes in that illness. Progress in Neuro-Psychopharmacology and Biological Psychiatry 35, 676-692.

Maes M, Mihaylova I, Kubera M, Uytterhoeven M, Vrydags N, Bosmans E (2010). Increased plasma peroxides and serum oxidized low density lipoprotein antibodies in major depression: markers that further explain the higher incidence of neurodegeneration and coronary artery disease. Journal of Affective Disorders 125, 287-294.

Miller AH, Maletic V, Raison CL (2009). Inflammation and its discontents: the role of cytokines in the pathophysiology of major depression. Biological Psychiatry 65, 732-741.

Mooy JM, Grootenhuis PA, de Vries H, Valkenburg HA, Bouter LM, Kostense PJ, Heine RJ (1995). Prevalence and determinants of glucose intolerance in a Dutch Caucasian population. The Hoorn Study. Diabetes Care 18, 1270-1273.

Musselman DL, Betan E, Larsen H, Phillips LS (2003). Relationship of depression to diabetes types 1 and 2: epidemiology, biology, and treatment. Biological Psychiatry 54, 317-329.

Narita K, Murata T, Hamada T, Takahashi T, Omori M, Suganuma N, Yoshida H, Wada Y (2007). Interactions among higher trait anxiety, sympathetic activity, and endothelial function in the elderly. Journal of Psychiatric Research 41, 418-427. 
Ocke MC, Bueno-de-Mesquita HB, Goddijn HE, Jansen A Pols MA, van Staveren WA, Kromhout D (1997a). The Dutch EPIC Food Frequency Questionnaire. I. Description of the questionnaire, and relative validity and reproducibility for food groups. International Journal of Epidemiology 26 (Suppl. 1), S37-S48.

Ocke MC, Bueno-de-Mesquita HB, Pols MA, Smit HA, van Staveren WA, Kromhout D (1997b). The Dutch EPIC Food Frequency Questionnaire. II. Relative validity and reproducibility for nutrients. International Journal of Epidemiology 26 (Suppl. 1), S49-S58.

Panagiotakos DB, Pitsavos C, Chrysohoou C, Tsetsekou E, Papageorgiou C, Christodoulou G, Stefanadis C (2004). Inflammation, coagulation, and depressive symptomatology in cardiovascular disease-free people: the ATTICA study. European Heart Journal 25, 492-499.

Paranthaman R, Greenstein AS, Burns AS, Cruickshank JK, Heagerty AM, Jackson A, Malik RA, Scott ML, Baldwin RC (2010). Vascular function in older adults with depressive disorder. Biological Psychiatry 68, 133-139.

Parker G, Gibson NA, Brotchie H, Heruc G, Rees AM, Hadzi-Pavlovic D (2006). Omega-3 fatty acids and mood disorders. American Journal of Psychiatry 163, 969-978.

Penninx BW, Kritchevsky SB, Yaffe K, Newman AB, Simonsick EM, Rubin S, Ferrucci L, Harris T, Pahor M (2003). Inflammatory markers and depressed mood in older persons: results from the Health, Aging and Body Composition study. Biological Psychiatry 54, 566-572.

Pizzi C, Manzoli L, Mancini S, Costa GM (2008). Analysis of potential predictors of depression among coronary heart disease risk factors including heart rate variability, markers of inflammation, and endothelial function. European Heart Journal 29, 1110-1117.

Ridker PM, Hennekens CH, Buring JE, Rifai N (2000). $\mathrm{C}$-reactive protein and other markers of inflammation in the prediction of cardiovascular disease in women. New England Journal of Medicine 342, 836-843.

Rothman KJ, Greenland S, Lash TJ (2008). Modern Epidemiology. Lippincott Williams and Wilkins: Philadelphia, PA.

Rybakowski JK, Wykretowicz A, Heymann-Szlachcinska A, Wysocki H (2006). Impairment of endothelial function in unipolar and bipolar depression. Biological Psychiatry 60, 889-891.

Schindhelm RK, van der Zwan LP, Teerlink T, Scheffer PG (2009). Myeloperoxidase: a useful biomarker for cardiovascular disease risk stratification? Clinical Chemistry 55, 1462-1470.

Schott LL, Kamarck TW, Matthews KA, Brockwell SE, Sutton-Tyrrell K (2009). Is brachial artery flow-mediated dilation associated with negative affect? International Journal of Behavioral Medicine 16, 241-247.

Schram MT, Stehouwer CD (2005). Endothelial dysfunction, cellular adhesion molecules and the metabolic syndrome. Hormone and Metabolic Research 37 (Suppl. 1), $49-55$.
Selvin S (1996). Statistical Analysis of Epidemiologic Data. Oxford University Press: New York.

Shen Q, Goderie SK, Jin L, Karanth N, Sun Y, Abramova N, Vincent P, Pumiglia K, Temple S (2004). Endothelial cells stimulate self-renewal and expand neurogenesis of neural stem cells. Science 304, 1338-1340.

Sherwood A, Hinderliter AL, Watkins LL, Waugh RA, Blumenthal JA (2005). Impaired endothelial function in coronary heart disease patients with depressive symptomatology. Journal of the American College of Cardiology 46, 656-659.

Spijkerman AM, Adriaanse MC, Dekker JM, Nijpels G, Stehouwer CD, Bouter LM, Heine RJ (2002). Diabetic patients detected by population-based stepwise screening already have a diabetic cardiovascular risk profile. Diabetes Care 25, 1784-1789.

Stehouwer CD, Gall MA, Twisk JW, Knudsen E, Emeis JJ, Parving HH (2002). Increased urinary albumin excretion, endothelial dysfunction, and chronic low-grade inflammation in type 2 diabetes: progressive, interrelated, and independently associated with risk of death. Diabetes 51, 1157-1165.

Thomas AJ, Morris C, Davis S, Jackson E, Harrison R, O'Brien JT (2007). Soluble cell adhesion molecules in late-life depression. International Psychogeriatrics 19, 914-920.

Tiemeier H, Hofman A, van Tuijl HR, Kiliaan AJ, Meijer J, Breteler MM (2003). Inflammatory proteins and depression in the elderly. Epidemiology 14, 103-107.

Unwin N, Shaw J, Zimmet P, Alberti KG (2002). Impaired glucose tolerance and impaired fasting glycaemia: the current status on definition and intervention. Diabetic Medicine 19, 708-723.

van Bussel BC, Henry RM, Schalkwijk CG, Ferreira I, Feskens EJ, Streppel MT, Smulders YM, Twisk JW, Stehouwer CD (2011a). Fish consumption in healthy adults is associated with decreased circulating biomarkers of endothelial dysfunction and inflammation during a 6-year follow-up. Journal of Nutrition 141, 1719-1725.

van Bussel BC, Schouten F, Henry RM, Schalkwijk CG, de Boer MR, Ferreira I, Smulders YM, Twisk JW, Stehouwer CD (2011b). Endothelial dysfunction and low-grade inflammation are associated with greater arterial stiffness over a 6-year period. Hypertension 58, 588-595.

Van der Zwan LP, Scheffer PG, Dekker JM, Stehouwer CD, Heine RJ, Teerlink T (2010a). Hyperglycemia and oxidative stress strengthen the association between myeloperoxidase and blood pressure. Hypertension 55, 1366-1372.

van der Zwan LP, Teerlink T, Dekker JM, Henry RM, Stehouwer CD, Jakobs C, Heine RJ, Scheffer PG (2009). Circulating oxidized LDL: determinants and association with brachial flow-mediated dilation. Journal of Lipid Research 50, 342-349.

van der Zwan LP, Teerlink T, Dekker JM, Henry RM, Stehouwer CD, Jakobs C, Heine RJ, Scheffer PG (2010b). Plasma myeloperoxidase is inversely associated with 
endothelium-dependent vasodilation in elderly subjects with abnormal glucose metabolism. Metabolism 59, 1723-1729.

Wendel-Vos GC, Schuit AJ, Saris WH, Kromhout D (2003). Reproducibility and relative validity of the Short Questionnaire to Assess Health-enhancing physical activity. Journal of Clinical Epidemiology 56, 1163-1169.

Wu KK (2003). Soluble thrombomodulin and coronary heart disease. Current Opinion in Lipidology 14, 373-375.
Yudkin JS, Stehouwer CD, Emeis JJ, Coppack SW (1999). C-reactive protein in healthy subjects: associations with obesity, insulin resistance, and endothelial dysfunction: a potential role for cytokines originating from adipose tissue? Arteriosclerosis, Thrombosis, and Vascular Biology 19, 972-978.

Zhao C, Deng W, Gage FH (2008). Mechanisms and functional implications of adult neurogenesis. Cell 132, 645-660. 